\title{
HUBUNGAN KARAKTERISTIK BIDAN PERUJUK D DENGAN KETEPATAN RUJUKAN KASUS KEGAWATDARURATAN MATERNAL DI PONEK RSU dr. SOEKARDJO KOTA TASIKMALAYA TAHUN 2016/2017
}

\author{
Aqmarina AA Dewi
}

\section{A. ABSTRAK}

Kematian ibu adalah kematian seorang wanita yang terjadi saat hamil, bersalin, atau 42 hari setelah persalinan. Salah satu cara meminimalisir kematian ibu (maternal) adalah dengan meningkatkan efektivitas penangangan rujukan kegawatdarurat ibu. Bidan sebagai tenaga kesehatan harus memiliki kesiapan untuk merujuk ibu atau bayi ke fasilitas kesehatan rujukan secara optimal dan tepat waktu, didalam melakukan rujukan kasus kegawatdaruratan obstetrik tidak terlepas dari karakteristik yang dimiliki bidan seperti : umur, pendidikan, lama kerja/pengalaman, pelatihan klinis dan tempat praktik. Penelitian ini bertujuan untuk mengetahui hubungan karakteristik bidan perujuk dengan ketepatan rujukan kasus kegawatdaruratan maternal di PONEK RSU dr. Soekardjo Kota Tasikmalaya Bulan Desember 2016 sampai dengan Bulan Maret 2017.

Jenis penelitian yang dilakukan pada penelitian ini adalah penelitian kuantitatif yang bersifat analitik dengan pendekatan cross sectional. Populasi dalam penelitian ini adalah seluruh bidan yang merujuk kasus-kasus kegawatdarutan maternal ke ruang PONEK RSU dr. Soekardjo Kota Tasikmalaya pada Bulan Desember 2016 sampai dengan Bulan Maret 2017. Teknik pengambilan sempel penelitian ini adalah dengan menggunakan Aksidental Sampling, yaitu sebanyak 31 bidan.

Berdasarkan hasil penelitian didapatkan bahwa antara karakteristik bidan perujuk (umur, pendidikan, lama kerja/pengalaman, pelatihan klinis dan tempat praktik), dengan ketepatan rujukan kasus kegawatdaruratan maternal di PONEK RSU dr. Soekardjo Kota Tasikmalaya Bulan Desember 2016 sampai dengan Bulan Maret 2017 terdapat hubungan yang signifikan yaitu untuk masing-masing

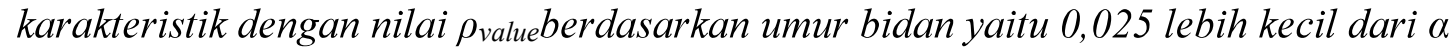
$(0,05)$, nilai $\rho_{\text {value }}$ berdasarkan pendidikan bidan yaitu 0,038 lebih kecil dari $\alpha(0,05)$, nilai $\rho_{\text {value }}$ berdasarkan pengalaman/lama kerja bidan yaitu 0,020 lebih kecil dari $\alpha$ $(0,05)$, nilai $\rho_{\text {value }}$ berdasarkan pelatihan klinis bidan yaitu 0,020 lebih kecil dari $\alpha$ $(0,05)$ dan nilai $\rho_{\text {value }}$ berdasarkan tempat praktik bidan yaitu 0,013 lebih kecil dari $\alpha$ $(0,05)$.

Kesimpulan dari penelitian adalah terdapat hubungan karakteristik bidan perujukdengan ketepatan rujukan kasus kegawatdaruratan maternal di Ponek RSU dr. Soekardjo Kota Tasikmalaya 2016/2017

\section{Kata kunci: Karakteristik, Bidan, Kegawatdaruratan}




\section{B. PENDAHULUAN}

Kematian ibuadalah kematian seorang wanita yang terjadi saat hamil,bersalin, atau 42 hari setelah persalinan dengan penyebab yang berhubungan langsung atau tidak langsung terhadap persalinan. (ICD10, 2012; WHO, 2014).Pada saat ini Angka Kematian Ibu diIndonesia masih sangattinggi. AngkaKematian Ibu (AKI) di Indonesia tahun 2015 akhirnya disepakati menggunakan hasil SUPAS (Survei Penduduk Antar Sensus) tahun 2015, yakni 305 per 100.000 kelahiran hidup (Litbang, 2016).

Di Provinsi Jawa Barat tahun 2015 berdasarkan data dari Dinas KesehatanProvinsi Jawa Barat menduduki peringkat tertinggi dalam jumlah AKI, didalam laporan tersebut AKI sebanyak 823 kasus (Dinkes Provinsi Jawa Barat, 2015).

Berdasarkan data yang penulis dapatkan di Dinas Kesehatan Kota praktik) dan variabel dependen adalah ketepatan rujukan.

\section{METODE PENELITIAN}

Instrumen atau alat pengumpulan data yang digunakan dalam penelitian ini berupa kuesioner yang merupakan pertanyaan tertulis yang digunakan untuk memperoleh informasi dari responden, sifat kuesioner tertutup karena jawaban sudah disediakan dan menggunakan lembar checklist yang isinya merupakan langkah dan persiapan bidan dalam melakukan proses rujukan dengan prinsip BAKSOKUDO.

Analisa ini digunakan untuk mendeskripsikan tiap variabel secara terpisah dengan membuat tabel distribusi frekuensi responden menurut berbagai variabel yang diteliti. Rumus perhitungan persentasenya adalah sebagai berikut

$$
\begin{aligned}
& \mathrm{P}={ }^{\mathrm{n}} \times 100 \% \\
& \mathrm{~N} \text { Keterangan } \\
& \mathrm{P}: \text { Presentasi } \\
& \mathrm{Fi}: \text { frekuensi teramati } \\
& \mathrm{N}: \text { jumlah responden }
\end{aligned}
$$

\section{D.HASILPENELITIAN \\ 1.Hasil Penelitian}

\section{A. Analisis Univariat \\ a.Karakteristik Responden}

Karakteristik responden meliputi : usia, pendidikan, pengalaman kerja, pelatihan klinis, tempat kerja. Berikut hasil penelitian ini akan dijelaskan dibawa ini : 


\section{Tabel 1}

Karakteristik Bidan Perujuk Di PONEK

RSU dr. Soekardjo Kota Tasikmalaya Bulan Desember 2016 - bulan Maret 2017

\begin{tabular}{c|c|c|c} 
Karakteristik & Kategori & $\begin{array}{c}\text { Frekuens } \\
\mathrm{i}\end{array}$ & $\%$ \\
\hline Umur & $\begin{array}{c}17-25 \\
\text { Tahun }\end{array}$ & 1 & 3,2 \\
\hline & $\begin{array}{c}26-35 \\
\text { Tahun }\end{array}$ & 13 & 41,9 \\
\hline & $\begin{array}{c}36-45 \\
\text { Tahun }\end{array}$ & 14 & 45,2 \\
\hline & $\begin{array}{c}46-55 \\
\text { Tahun }\end{array}$ & 3 & 9,7 \\
\hline Pendidikan & D-3 & 22 & 71,0 \\
\hline & D-4 & 8 & 25,8 \\
\hline Pengalaman & S-1 & 1 & 3,2 \\
\hline Kerja & $>10$ tahun & 12 & 38,7 \\
\hline Pelatihan & Tidak & 19 & 61,3 \\
\hline Klinis & Ya & 19 & 38,7 \\
\hline & BPM & 7 & 22,6 \\
\hline Tempat & PKM & 5 & 16,1 \\
\hline Kerja & PKM DTP & 8 & 25,8 \\
\hline & PKM & 11 & 35,5
\end{tabular}

\section{E. PEMBAHASAN}

a.Tabulasi Silang Karakteristik Bidan Perujuk

$\begin{array}{lr}\text { Berdasarkan Usia } & \text { dengan } \\ \text { Ketepatan Rujukan } & \text { Kasus } \\ \text { Kegawatdaruratan Maternal } & \text { Hasil } \\ \text { tabulasi silang karakteristik bidan } \\ \text { perujuk berdasarkan usia dengan } \\ \text { ketepatan rujukan } & \text { kasus } \\ \text { kegawatdaruratan maternal di RSU } \\ \text { dr. Soekardjo Kota Tasikmalaya } \\ \text { tahun 2016/2017 diketahui bahwa }\end{array}$

persentase terbesar adalah bidan perujuk pada kelompok usia 26-35 tahun dengan tidak sesuai dalam ketepatan rujukan kasus kegawatdaruratan maternal yaitu sebanyak 11 orang $(84,6 \%)$. Hasil analisis menggunakan uji linear by linear association test diperoleh pvalue sebesar 0,025, hal ini menunjukkan bahwa $\rho$ valuelebih kecil dari $\alpha(0,025<0,05)$. Dengan demikian berarti bahwa terdapat hubungan antara usia bidan perujuk 
denganketepatan rujukan pada kasus kegawatdaruratan maternal.

Usia merupakan suatu indikator umum tentang kapan suatu perubahan akan terjadi. Usia menggambarkan pengalaman dalam diri seseorang sehingga terdapat keragaman tindakan berdasarkan usia yang dimiliki (Sudjarwo, 2009). Menurut penelitian Santoso dan Ismael (2009), meningkatnya usia seseorang, akan meningkat pula kebijaksanaan dan kemampuan seseorang dalam mengambil keputusan dan berpikir rasional.

Dengan demikian hasil penelitianini menunjukkan bahwa usia bidan tidakmempengaruhi dalam melakukan rujukankegawatdaruratan karena baik usia yangmasih muda maupun yang sudah tua sering terjadi ketidaktepatan dalam melakukan Rujukan.

Tabulasi Silang Karakteristik Bidan Perujuk berdasarkan Pendidikan dengan Ketepatan Rujukan Kasus Kegawatdaruratan Maternal Hasil tabulasisilang karakteristik bidan perujuk berdasarkan pendidikan dengan ketepatan rujukan kasus kegawatdaruratan maternal di RSU dr.Soekardjo Kota Tasikmalaya tahun 2016/2017 diketahui bahwa persentase terbesar adalah bidan perujuk padakelompok tingkat pendidian D3 dengantidak sesuai dalam ketepatan rujukankasus kegawatdaruratan maternal yaitusebanyak 17 orang (77,3\%). Hasil analisismenggunakan uji fisher's exact testdiperoleh pvalue sebesar 0,038, hal inimenunjukkan bahwa $\rho$ value lebih kecil daria $(0,038$ $<$ 0,05). Dengan demikian berartibahwaterdapathubunganantara pendidikanbidan perujuk denganKetepatan rujukan pada kasus kegawatdaruratan maternal. Pendidikan dianggap memiliki peranan penting dalam menentukan kualitas manusia melalui pendidikan. Manusia dianggap akan memperoleh pengetahuan dan dengan pengetahuan manusia akan dapat membangun keberadaan hidupnya dengan lebih baik. Implikasinya semakin tinggi tingkat pendidikan hidup manusia akan semakin berkualitas, dimana semakin tinggi pendidikan maka seseorang akan semakin mudah untuk menerima halhal yang baru dan mudah menyesuaikan diri dengan hal- hal baru tersebut, tetapi tidak menutup kemungkinan bahwa pendidikan rendah punya pengetahuan dan sikap yang lebih baik (Machfoedz, 2010).

Dengan demikian hasil penelitian ini menunjukkan bahwa pendidikan bidan mempengaruhi dalam melakukan rujukan kegawatdaruratan karena pendidikan Bidan yang diakui pemerintah dan organisasi profesi harus memiliki kompetensi dan kualifikasi untuk diregister, sertifikasi dan atau secara sah mendapat lisensi untuk menjalankan praktik d kebidanan.

c. Tabulasi Silang Karakteristik Bidan Perujuk Berdasarkan Pengalaman dengan Ketepatan Rujukan Kasus Kegawatdaruratan Maternal

Hasil tabulasi silang karakteristik bidan perujuk berdasarkan pengalaman Dengan ketepatan rujukan kasus kegawatdaruratan maternal di RSU dr.Soekardjo Kota Tasikmalaya 
tahun 2016/2017 diketahui bahwa persentase terbesar adalah bidan perujuk memiliki pengalaman kerja $<10$ tahun dengan tidak sesuai dalam ketepatan rujukan kasus kegawatdaruratan maternal yaitu sebanyak 11 orang $(91,7 \%)$. Hasil analisis menggunakan uji fisher's exact test diperoleh $\rho$ value sebesar 0,020, hal ini menunjukkan bahwa $\rho$ value lebih kecil dari $\alpha(0,020<$ 0,05). Dengan demikian berartibahwaterdapat hubungan antarapengalaman bidan perujukdenganketepatanrujukanpada kasuskegawatdaruratan

maternalPengalaman

adalahguruyangbaik, oleh sebab itu pengalamanmerupakan sumber pengetahuan, ataupengalaman

itumerupakan suatu carauntukmemperoleh

pengetahuan.Pengalaman pribadi dapat digunakansebagai upaya memperoleh pengetahuan.Hal inidilakukan dengan cara mengulangkembali pengalaman yang diperoleh dalammemecahkan persoalanyang dihadapipada masa yang lalu (Notoatmodjo, 2007).

Dengan demikian hasil penelitianini menunjukkan bahwa pengalamanbekerja

bidanmempengaruhi

dalammelakukan rujukan

kegawatdaruratankarena dengan pengalaman yang baikbidan dapat mempertahankan dengan apayang menjadi tugas dan fungsinya sertadengan pengalaman yang kurang baikdapat melakukan perubahan menjadi lebihbaik. d. Tabulasi Silang Kärakteristik Bidan Perujuk Berdasarkan Pelatihan Klinis denganKetepatan Rujukan asus Kegawatdaruratan Maternal

$\begin{array}{lr}\quad \text { Hasil tabulasi } & \text { silang } \\ \text { karakteristikbidan } & \text { perujuk } \\ \text { berdasarkan } & \text { pelatihan } \\ \text { klinisdenganketepatan } & \text { rujukan }\end{array}$
kasuskegawatdaruratan maternal di RSU dr.Soekardjo Kota Tasikmalayatahun2016/2017 diketahui bahwa persentaseterbesar adalah bidan perujuk tidakmengikuti pelatihan klinis dengan tidaksesuai dalam ketepatan rujukan kasuskegawatdaruratan maternal yaitusebanyak 11 orang $(91,7 \%)$. Hasil analisismenggunakan uji fisher's exact testdiperoleh $\rho$ value sebesar 0,020, hal inimenunjukkan bahwa $\rho$ value lebih kecil daria $(0,020<0,05)$. Dengan demikian berartibahwa terdapat hubungan antara pelatihan klinis bidan perujuk dengan ketepatan rujukan pada kasus kegawatdaruratan maternal. Pelatihan

klinis kegawatdaruratan merupakan pelatihan yang duperuntukan bagi bidan/calon bidan yang bertujuan untuk meningkatkan pengetahuan dan keterampilan untuk membawa perubahan di bidang kesehatan, terutama dalam kasus kegawatdaruratan maternal dan neonatal. Tujuan dari pelatihan ini adalah dapat memberikan pelayanan yang tepat atau asuhan kebidanan yang tepat dalam penanganan atau perujukan serta dapat melakukan segala tindakan dan asuhan yang diberikan dalam seluruh aspekpengabdiandengankompetensip rofesinya sebagai seorang bidan (Masudik, 2015).Dengan demikian 
hasil penelitian ini menunjukkan bahwa pelatihan klinis bidan mempengaruhi dalam melakukan rujukan kegawatdaruratan karena itu, sangat penting sekali bahwa bidan dapat mengikuti pelatihan karena dapat mencegah terjadinya ketidaktepatan dalamproses rujukan kegawatdaruratan kebidanan.

e. Tabulasi Silang Karakteristik Bidan Perujuk Berdasarkan Tempat kerja denganKetepatan Rujukan Kasus Kegawatdaruratan Maternal

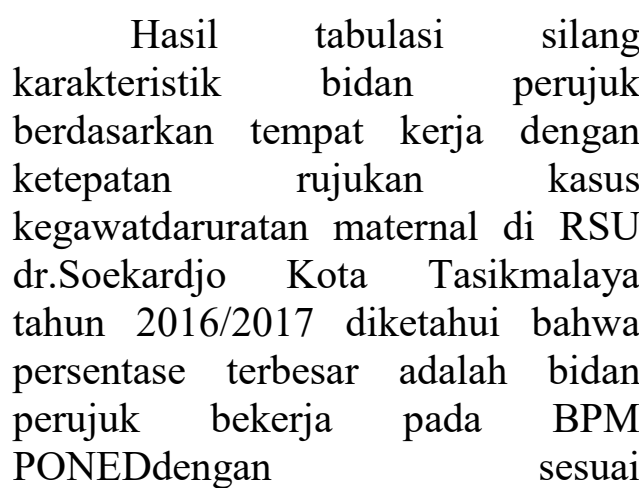
dalamketepatanrujukankasuskegawat daruratan maternalyaitu sebanyak 7 orang (63,6\%).Hasil analisis menggunakan uji linear by linearassociation diperoleh pvalue sebesar0,013, hal ini menunjukkan bahwa $\rho v a l u e$ lebih kecil dari $\alpha$ $(0,013<0,05)$. Dengan demikian berarti bahwa terdapat hubungan antara tempat kerja bidan perujuk denganketepatan rujukan pada kasus kegawatdaruratan maternal.

Puskesmas mampu PONED memiliki kemampuan untuk memberikan pelayanan langsung kepada ibu hamil, ibu bersalin, ibu nifas dan bayi baru lahir baik yang datang sendiri atau atas rujukan kader/masyarakat, bidan di desa dan puskesmas. Puskesmas mampu
PONED dapat melakukan pengelolaan kasus dengan komplikasi tertentu sesuai dengan tingkat kewenangan dan kemampuannya atau melakukan rujukan pada RS PONEK (Depkes RI, 2007).

Dengan demikian hasil penelitian ini menunjukkan bahwa puskesmas PONED merupakan suatu usaha pemerintah untuk mendukung tercapainya tujuan pembangunan kesehatan nasional, yakni meningkatkan kesadaran, kemauan dan kemampuan hidup sehat bagi orang yang bertempat tinggal di wilayah kerja puskesmas agar terwujud derajat kesehatan yang setinggi-tingginya.

\section{F. KESIMPULAN DAN SARAN}

1. Karakteristik bidan perujuk meliputi : umur bidan perujuk adalah 36-45 tahun sebesar $(45,2 \%)$, pendidikan D3Kebidanan sebesar (71,0\%), pengalaman kerja $>10$ tahun sebesar $(61,3 \%)$, telah melakukan pelatihan klinis sebesar $(61,3 \%)$, dan tempat kerja di PKM PONED sebesar $(35,5 \%)$.

2. Persentase terbesar dalam ketepatan rujukan kasus kegawatdaruratan maternal adalah bidan tidak sesuai dengan protap sebanyak 20 bidan (64,5\%).

3. Berdasarkan hasil penelitian menunjukkan bahwa ada hubunganantara karakteristik bidanperujuk dengan ketetapan rujukan kasus kegawatdaruratan. Nilai $p$ value untuk dengan ketepatan rujukan kasus usia 
sebesar 0,025 , pendidikan sebesar 0,038 , pengalaman sebesar 0,020 , pelatihan klinis sebesar 0,020 dan tempat kerja sebesar 0,013 lebih kecil daripada nilai $(0,05)$.

\section{Saran}

Lebih meningkatkan dalam menangani kasus rujukan sesuai dengan standar operasional prosedur. Selain itu juga lebih meningkatkan kualitas dan profesionalisme bidan dalam penanganan rujukan kasus kegawatdaruratan kebidanan.

\section{G.DAFTAR PUSTAKA}

Angka Kematian Ibu Indonesia 2015

telahDisepakati.http://www.lit bang.go.id. diakeses pada 01tanggal $30 \quad$ Agustus 2016.Masudik, Dkk. (2015). Basic Obstetric DanNeonatalLifeSupportBon els,GADAR Medik Indonesia, Bekasi.

Maryanti D, Setikasari M. (2009). Buku

AjarKesehatanReproduksi Terapi danPraktikum, Fitramaya, Yogyakarta.

Notoatmodjo S. (2007) Promosi KesehatandanIlmuPerilaku.C etakan I,PT.Rineka Cipta, Jakarta.

PP IBI. (2008). Bidan Menyongsong MasaDepan Cetakan ke XI, Jakarta.RSU Tasikmalaya (2015). Angka Persalinandalam menangani kasus rujukan sesuaiPervaginam. 2015. Tasikmalaya.
RSU Tasikmalaya. (2016). Angka 10 BesarPenyakit Rujukan di Ruang PONEKPeriode bulan Januari - September.2016. Tasikmalaya.

RSU Tasikmalaya. (2016). Angka Kejadianpenangananrujukan kasusPersalinanPervaginam.2 016. Tasikmalaya.

RSUTasikmalaya.(2016).JumlahKa susRujukan di Ruang PONEK Periodebulan Januari - September. 2016.Tasikmalaya.

${ }^{\mathrm{RSU}}$ Tasikmalaya.(2016).Jumlah KasusRujukanyangMenyi mpangdariBAKSOKUDO di Ruang PONEKOktober $2016 \quad-02$

Asrinah, Putri,Sulistyotini danMuflihah. 2016. Tasikmalaya.(2010).Konsep Kebidanan. Graha

Soepardan, Suryani. (2008). KonsepIlmu, Yogyakarta.Kebidanan, EGC, Jakarta.

Cherin.(2009).HubunganPengalama ndenganpengetahuanhttp//ww w.wordpress.com. Diakses padatanggal 30 September 2016.

World

Health Organization(WHO).( 2014)Pelayanan Kesehatan Ibu di

FasilitasKesehatanDasardanRu jukan,Kementerian KesehatanRepublikIndonesia. World HelathOrganization(WHO), Jakarta.

Depkes RI. (2007). Pedoman Teknis Maternal-Perinatal di Tingkat Kabupaten/Kota, Departemen Kesehatan RI.

Depkes RI.(2009). Data Penduduk SasaranProgram 
PembangunanKesehatan2007-

2011.

Departemen

KesehatanRI.

Dinas Kesehatan Kota Tasikmalaya. (2016)Angka Kematian Ibu Tahun 2015.

Dinas Kesehatan Jawa Barat. (2014). AngkaKematian Ibu. Diakses pada

tanggal30Agustus2016.www.di skes.jabarprov.go.id

DwikhantiR. HubunganantaraKompetensi( $P$ engetahuan, Sikap danKeterampilan)BidanTerhad ap

KetepatanRujukanPadaKasusP reeklampsiadiKabupatenKaraw ang. Kabupaten Kawarang.

KementerianKesehatanRepublikIndo nesia.(2015).BukuSakuPelayan anKesehatan Ibu di Fasilitas KesehatanDasar dan Rujukan. Jakarta. 